\title{
A HOLISTIC GROUP PSYCHOTHERAPEUTIC INTERVENTION FOR THE TREATMENT OF IRRITABLE BOWEL SYNDROME AND ITS COMORBID DEPRESSION AND ANXIETY
}

\section{Ms CM Bush}

Department of Psychology, Rand Afrikaans University

\section{Prof. HG Pretorius}

Department of Psychology, Rand Afrikaans University

\author{
Prof. AD Stuart \\ Department of Psychology, Rand Afrikaans University \\ Corresponding author: adst@lw.rau.ac.za
}

Keywords: Irritable Bowel Syndrome (IBS); Psychosomatic Disorders; Holistic Group Psychotherapy; Depression; Anxiety; Gastrointestinal symptoms; Psychotherapeutic intervention

\begin{abstract}
The aim of this study was to ascertain the effects of a holistic short-term group intervention in the treatment of /rritable Bowel Syndrome (IBS) with comorbid depression and anxiety. The sample consisted of 24 South African women who had been diagnosed with severe IBS. Furthermore, each participant had to have associated moderate to severe depression and anxiety. The group design was a pre-test, post-test control group design where the experimental group $(n=12)$ received group intervention and the members of the control group $(n=12)$ received no intervention until after completion of the research. All the participants completed the Functional Bowel Disorder Severity Index and the Depression and Anxiety subscales of the Personality Assessment Inventory before commencement of group therapy for Group 1 and one month after completion of this intervention. The effect of the intervention was determined by utilising comparative statistics. The findings indicate that holistic short-term group therapy results in significant improvement in terms of depression and anxiety scores, but that IBS symptom severity remains unchanged. It is recommended that further research be conducted to ascertain whether holistic group therapy of a longer duration has a greater impact on the IBS symptom severity.
\end{abstract}

\section{OPSOMMING}

Die doel van die studie was om die effek van ' $n$ holistiese korttermyn groepsintervensie op die behandeling van Prikkelbare Dermsindroom (PDS), met komorbiede depressie en angs, te bepaal. Die steekproef is uit 24 Suid-Afrikaanse vroue saamgestel wat gediagnoseer is met ernstige PDS. Verdermeer moes elke deelnemer geassosieerde matige tot ernstige depressie en angs hê. Die groepsontwerp was 'n pre-toets, post-toets-kontrolegroep-ontwerp waarin die eksperimentele groep $(n=12)$ ' $n$ groepsintervensie ontvang het en die lede van die kontrolegroep $(n=12)$ geen intervensie ontvang het totdat die navorsing afgehandel was nie. Al die deelnemers het die Functional Bowel Disorder Severity Index en die Depressie- en Angssubskale van die Personality Assessment Inventory voltooi voor die aanvang van groepsterapie vir Groep 1 asook een maand later na voltooing van die intervensie. Die effek van die intervensie is deur middel van vergelykende statistieke bepaal. Die bevindings dui aan dat holistiese korttermyngroepsintervensie aanleiding gee tot betekenisvolle verbetering in terme van depressie- en angstellings, maar dat die ernstigheid van PDS-simptome onveranderd bly. Dit word aanbeveel dat verdere navorsing aangevoer word om te bepaal of langer holistiese groepsterapie 'n groter impak het op die ernstigheid van PDS-simptome. 


\section{INTRODUCTION}

Irritable Bowel Syndrome (IBS) is a disorder, which is centuries old, and yet little light has been shed on the successful treatment of this symptom complex. IBS symptoms are expressed in various forms. More common are those located in the mid to lower abdominal tract which include chronic or severe abdominal pain, abdominal distention, altered bowel habit (diarrhoea, constipation or a mixed stool pattern) and a passage of mucus (Drossman, 1994:11). Less common are symptoms within the upper gastrointestinal tract, which could include epigastric pain, dyspepsia, nausea and heartburn. Seemingly unrelated symptoms such as backache, dyspareunia or bladder irritability have also been positively correlated with IBS. Psychosocial factors such as depression and anxiety have been strongly associated with IBS and this together with the absence of a pathological indication further fuels the diagnostic dilemma. The incidence of psychiatric illness found in IBS health care seekers ranges between $70 \%$ to $90 \%$, with depression and anxiety predominating (Lydiard, Laraia, Howell \& Ballenger, 1986:470).

\section{IRRITABLE BOWEL SYNDROME}

For the purposes of this study, IBS may be defined as a syndrome which embraces not only the clinician's signs of the disorder, but also the individual's experience of the illness (Stuart, Pretorius, Stanley, Rossouw, Nel, Dolan \& Bush, 1999:2). The individual's experience of illness primarily focuses on the mid and lower gastrointestinal tract where common symptoms of abdominal pain, bloating, flatulence and disordered defecation - either diarrhoea, constipation or both, occur. As Kellow, Langeluddecke, Eckersley, Jones and Tennant (1992:55) describe, IBS may be chronic or persistent and may flare up episodically, varying in frequency and severity. Upper gastrointestinal symptoms such as dyspepsia, nausea, and heartburn are also found, as are non-gastrointestinal symptoms such as migraine, non-cardiac chest pain and fatigue. The clinician needs to be aware of seemingly unrelated symptoms such as dyspareunia, bladder irritability or urinary frequency and referred colonic pain to the back or thigh. It is also essential that strong psychosocial correlates such as depression, anxiety and stress be evaluated in viewing the individual holistically.
According to the 1988 Rome Criteria, Thompson (1984:307) postulates that in order to diagnose IBS, individuals must have abdominal pain or discomfort for 3 months consecutively, that is (i) relieved with defecation; (ii) associated with a change in the consistency of stool, and two or more of the following on at least $25 \%$ of occasions or days: (iii) altered stool frequency; (iv) altered stool form (lumpy and hard, or loose and watery); (v) altered stool passage (straining and urgency or feeling of incomplete evacuation); (vi) passage of mucus, and (vii) bloating or feeling of abdominal distension.

Not only does one need to be able to identify and recognize the above symptoms, but their severity also needs to be taken into account. Drossman, Thompson and Whitehead (1992:180) distinguishes between mild, moderate and severe symptoms. Mild symptoms are those where a person has no functional impairment nor are they psychologically disturbed. Moderate symptoms are experienced by a smaller number of people whose intermittent absenteeism from work is reported. These people closely associate a trigger event with the onset of symptoms, e.g. stress or diet. They are slightly more psychologically impaired than the former group. Severe symptoms often occur in individuals having a diagnosis of comorbid anxiety, depression and somatisation. Drossman and Thompson (1992:1011) emphasise a history of abuse combined with an abnormal reaction to illness. These people constantly seek reassurance regarding the disease, insist on unnecessary, invasive and excessive diagnostic measures, deny the psychological components of their disorder and place full responsibility on the doctor for an unrealistic cure (Guthrie, Creed, Dawson \& Tomenson, 1991:454).

The onset of IBS is generally in late adolescence (Walker, Roy-Byrne, Katon, Li, Amos \& Jiranek, 1990:1657) and it seldom occurs after 60 . The disorder is prominently found in white women who are 35 years of age and younger (Drossman, et al. 1992:177).

In a South African study conducted by Segal and Walker (1984:73), a low incidence of IBS was found in rural black South Africa, but the syndrome was found to be more prevalent in urban black South Africa.

Correlations between psychiatric illness and IBS healthcare seekers have been well researched. More 
specifically, $70 \%$ to $90 \%$ of IBS subjects are said to have diagnosable psychiatric problems with depression and anxiety predominating (Lydiard, et al. 1986:471).

Svedlund, Sjodin, Dotevall and Gillberg (1984:200), attempted to measure the incidence and impact of psychological symptoms on IBS before assigning a treatment programme. They found that $98 \%$ of the IBS sample reported anxiety, with $70 \%$ of the participants experiencing a mild comorbid depression. They thus associated IBS with these affective disorders. Subsequently much research has been conducted that disputes these mild depressive symptoms (Kellow, et al. 1992:55). Later South African evidence in support of major depression in IBS individuals can be found in research by Els, Gagiano, Grundling, van Zyl and Joubert (1995:1369) who report major depression in 38\% of their IBS participants. They also report $60 \%$ of their participants as presenting with anxiety syndromes and an overall $71 \%$ of participants had either anxiety and/or depressive symptoms.

\section{MOOD DISORDERS}

Important mood disorders to consider in association with IBS are Major Depressive Disorder and Dysthymia (Keller, 1996:10).

\section{Major Depressive Disorder}

The DSM IV-R (in Kaplan, Sadock \& Grebb, 1994:24) classifies a Major Depressive Disorder as a change from previous functioning with at least two weeks of depressed mood, with a loss of interest and accompanied by four additional symptoms of depression. These symptoms include altered appetite, weight change, sleep or psychomotor activity, anhedonia, lethargy, feelings of worthlessness or guilt, poor concentration or decisionmaking skills and suicidal ideation or death ruminations.

\section{Dysthymia}

Dysthymia, according to Kaplan, et al. (1994:41), implies a temperamental dysphoria - an innate tendency to be depressed. Dysthymia needs to be differentiated from Major Depressive Disorder, as it is a chronic and less severe form of depression. The incidence, which has been apparent for two years or longer, is much lower, occurring in $3-5 \%$ of the general population.

\section{ANXIETY BASED DISORDERS}

Anxiety serves to alert one to the potential of an internal or external stressor - thereby reducing its likelihood (Kaplan, et al. 1994:47). Whether an event is perceived as stressful or not, depends on the person's resources, their support systems, their coping mechanisms and their psychological defenses. Pathological anxiety or an anxiety-based disorder is characterised by marked distress or impairment in social, occupational or academic functioning (Sten \& Bouwer, in Allwood \& Gagiano, 1997:87). Studies on anxiety in IBS have also focused on State-anxiety versus Trait-anxiety. Spielberger (1966:4) defines State-anxiety as a transitory state of emotional arousal, which, he believes, varies in intensity and fluctuates with time. Trait-anxiety, (Spielberger, 1966:4), is defined as an acquired behavioural tendency predisposing the individual to perceive a wide range of objectively non-threatening situations as dangerous.

Compared with anxiety in the normal population, stateanxiety in IBS individuals has consistently been found to be high (Feigtner, et al. in Langeluddecke, 1985:219). Esler and Goulston (1973:17) comment on how diarrhoea-predominant IBS individuals are far more anxious than individuals who have other gastrointestinal (GI) disorders which are not specifically IBS related. Furthermore, Hillman, et al. (in Langeluddecke, 1985:220) were able to show a positive correlation between severity of anxiety symptoms and severity of Gl symptoms.

\section{Generalised Anxiety Disorder}

Generalised Anxiety Disorder is characterised by excessive anxiety or worry, on most days for six months or more. There is no apparent stressor. Somatic symptoms of restlessness, early fatigue, poor concentration and irritability may prevail.

\section{Panic Disorder}

Panic Disorder is characterised by panic attacks discrete periods of intense fear or discomfort. Accompanying the attack are autonomic symptoms such 
as palpitations, tachycardia, trembling, dyspnoea (shortness of breath), choking, sweating, nausea, dizziness, hot flushes and a fear of death. These symptoms may mimic a heart attack and the individual begins to develop anticipatory anxiety for subsequent attacks. Lydiard, et al. (1986:472) in their study on whether Panic Disorder presents as IBS, state that there is such a frequent overlap of Gl symptoms and anxiety disorders, that they suggest that some IBS patients actually have a primary anxiety disorder such as a panicrelated disorder.

\section{COMBINED DEPRESSION/ANXIETY SYNDROMES}

Keller (1996:12) describes how in the 1980's depression and anxiety were regarded as pure and separate syndromes. This belief has undergone a paradigm shift. Depression is associated with anxiety symptoms in $67 \%$ of cases and in $33 \%$ of these, panic attacks occur. Depression, he believes, occurs in $40 \%$ of individuals who are primarily anxious and in $33 \%$ of those with Panic Disorder.

The effect of a Combined Anxiety and Depressive Syndrome on individuals is that they become more ill and more chronically impaired. The average time of recovery for depression with anxiety, according to Keller (1996:13), is six months as opposed to three months without anxiety. Comorbid anxiety according to Keller (1996:13) is the rule rather than the exception.

Walker, et al. (1990:1657) sought to compare the incidence of psychiatric illness in IBS participants as opposed to the organically impaired Irritable Bowel Disorder participants, referred to as IBD. He concluded that $61 \%$ of the IBS participants had a history of lifetime depression, versus $16 \%$ of the IBD participants. Furthermore, $21 \%$ of IBS participants had current depression as opposed to $5 \%$ of the IBD participants. A lifetime diagnosis of anxiety was made in only $11 \%$ of IBD participants versus $54 \%$ of IBS participants. Panic Disorder was found to be in $29 \%$ of IBS participants versus none in the IBD group. This suggests that functional gastrointestinal disorders are far more likely to have a comorbid psychiatric illness than the organically disordered GI participants.

\section{PROBLEM STATEMENT}

There have been many studies which have highlighted the effectiveness of diverse therapeutic interventions in the management of the patient with IBS. However, there have been many restrictions or limitations, which need to be reiterated. Firstly, due to the previous dualistic treatment approach where mind and body were targeted, psychology was predominantly absent in the treatment equation. Secondly, a lack of a coherent theory of IBS also influenced researched methodologies, where samples were skewed or biased and where there was limited control over all the variables. Therapeutic interventions were often adopted haphazardly, as it was difficult to assess which intervention was more effective for which participant. This served to limit the generalisability of the psychological treatments.

Furthermore, it was only with the shift to a biopsychosocial approach (Drossman, 1989:159) that a theoretical platform for a multicomponent perspective was legitimised. There is little evidence, in a search of the international literature, to show that there has been a fully integrated approach applied to the treatment of people with IBS either individually or in groups. Rather, a "shotgun" approach to psychotherapy utilising a few models in combination such as cognitive, behavioural end hypnotherapy has been adopted.

There has been a dearth of South African studies with requests for more local data. A South African study by Dolan (2000) has been the only holistic approach to the treatment of individuals with IBS, which embraced both medical and psychotherapeutic interventions. To date, there has been no South African or overseas literature that has applied or evaluated holistic short-term group psychotherapeutic intervention in the treatment of IBS and its comorbid depression and anxiety.

There have been strong recommendations for group psychotherapy in IBS individuals who also have a comorbid anxiety and depression. With the prevalence so high and the cost to the economy and the individual so great, effective holistic group psychotherapy seems to be a logical option.

\section{AIM OF THE STUDY}


Considering the high prevalence of IBS, the debilitating nature of the disease and the limited effectiveness of most treatments, it is the aim of this study to consider IBS treatment more holistically. The specific aim then of the study is to determine the effect of a holistic shortterm group intervention in the treatment of IBS with its comorbid depression and anxiety. The intervention is described in the section following an explication of the methodology.

\section{METHODOLOGY}

\section{Research design}

This is a between groups experimental design consisting of two groups. Group 1 received the treatment and Group 2 received no treatment. It was based on a pre-test, posttest control group design. The effect of the intervention was largely reflected in the amount of change from pretest to post-test.

Due to the fact that this study incorporated short-term treatment and given that Yalom's (1970:9) principle of homogeneity was adopted, little randomisation was applied. Discussion of the sample below will highlight the randomisation issues further.

\section{Sample}

The sample for this study, which consisted of 24 white female adults (average age was 40 years), was selected from a pool of approximately 180 adult females who had been positively diagnosed by either a general practitioner or a gastroenterologist as having severe IBS symptoms. Each participant had associated moderate to severe depression and anxiety. Approximately $50 \%$ of the participants had a tertiary education and $33 \%$ of the remaining $50 \%$ had at least a matric qualification. In terms of occupational status, $42 \%$ of the sample were professionals and a further $37 \%$ were in a business position. Referral to the research centre was through the media where participants were briefed regarding the study and were invited to be part of the sample group. Other sources of referral were the participants' medical doctor, dietician or word of mouth.

Due to the marketing exercise described above, there is little chance that the obtained sample was truly random.
Unfortunately, this limits the generalisability of the findings to all South African population groups. Furthermore, a self-selected group of health-care seekers is likely to have been targeted which also does not represent the wider IBS population. Generalisation to the white female health care seekers in South Africa is probably appropriate.

\section{Selection Instruments}

The Biographical Questionnaire was developed as a means of requesting various personal details (e.g. name, address, gender, race etc.), family history, emotional or psychological problems, a history of treatment and other important data (e.g. smoking habits, physical activity level etc.). Based on the information obtained in this questionnaire, all male participants were excluded as well as children younger than 20 .

The IBS Client Questionnaire was conducted by Drossman, Thompson and Talley (in Drossman, 1994:12). It is based on the Rome criteria for IBS in order to verify a positive IBS diagnosis. This questionnaire focuses on the nature, frequency and duration of the client's IBS symptoms. The questionnaire was used to verify a doctor's referral where IBS was indicated. Only on verification could a referred patient participate in the study. These measures were taken for ethical reasons to ensure that any other organic pathology was controlled for.

\section{The Functional Bowel Disorder Severity Index} (FBDSI) is a standardised scoring method designed by Drossman, Zhiming, Toner, Diamant, Creed, Thompson, Read, Babbs, Barreiro, Bank, Whitehead, Schuster and Guthrie (1995:990) as a means of assessing both the nature and the severity of functional bowel disorders which present either in the mid or lower gastrointestinal tract. The FBDSI was utilised as both a selection instrument and a measuring instrument.

Drossman, et al. (1995:991) provide evidence which attests to the reliability of the FBDSI based on the following findings:

1) Visual analogue scales have been shown to be reliable and responsive in assessing pain severity (Duncan, Bushnell \& Lavigne, 1989:297).

2) A diagnosis of chronic functional abdominal pain, and 
the frequency of doctor visits is not likely to change during the time frame ( $<2$ weeks) within which test-retest reliability is established.

3) Repeating the FBDSl as a measuring instrument in another sample of IBS individuals assessed the replicability of the scale. The distribution of scores closely approximated those of the original study, suggesting that the FBDSI can reliably determine the range of illness in replicated studies (Drossman, et al. 1995:991).

The validity of the FBDSI scale was determined both in terms of face and convergent validity by means of regression analysis (Drossman, et al. 1995:992). In terms of face validity, individuals with more severe pain remains constant and who frequently consult doctors are likely to be judged as having more severe illness. Convergent validity was established since the same items repeatedly emerged from several different types of regression methods. The Kruskal-Wallis test was used to test construct validity by comparing the FBDSI scores to the degree to which symptoms interfered with daily activities.

The Personality Assessment Inventory (PAI) was selected as the instrument used in this study to assess the presence and severity of depression and anxiety in all IBS individuals. The PAI is both a selection and a measuring instrument as participants in this study could only be selected on the basis of a positive diagnosis of moderate to severe depression and anxiety. Furthermore, the participant's depression and anxiety was then measured both at the pre-test and at the posttest levels in order to verify the treatment effects.

The PAl is a self-administered, objective inventory of adult personality. Included in the PAl are 11 clinical scales that assess the presence of actual clinical syndromes. For the purposes of this study, only the scores on the Depression and Anxiety scales were included.

Morey (1991:3) reports adequate internal consistency reliability for the PAI and an average correlation of 0.85 in terms of test-retest reliability. According to Morey (1991:3), the process of establishing the validity of the PAl involved firstly the concurrent administration of the best available diagnostic indicators to various samples to determine their convergence with corresponding PAI scales. Secondly, diagnostic judgements concerning clinical behaviours were examined to determine if the
PAl correlates were consistent with hypothesised relationships. The diagnostic indicators used included the Minnesota Multiphasic Personality Inventory and the NEO Personality Inventory. It is clear from the available data that the validity of each sub-scale within the PAI was confirmed.

\section{Selection of subjects}

The sample consisted of 24 South African women who had been positively diagnosed with severe IBS by either a gastroenterologist or a general practitioner. Each participant had to have associated moderate to severe depression and anxiety. The participants were divided into two groups of twelve members each. Group 1 was the experimental group and Group 2 was the control group. The group design was a pre-test, post-test control group design where participants in Group 1 (the experimental group) received group intervention and the participants in Group 2 (the control group) received no intervention until after completion of the research study. All the participants completed the IBS Severity Index Questionnaire and the Depression and Anxiety subscales of the Personality Assessment Inventory before commencement of group therapy for Group 1 and again one month after completion of this intervention. The effect of the intervention was determined utilising comparative statistics with reference to the pre-test versus post-test scores.

\section{Procedure}

Each participant underwent an intake interview where an overview of the research was presented. Ethical requirements of openness were thus met. Participants were also requested to produce their doctor's referral letter stating a positive IBS diagnosis. During the second appointment the selection instruments were completed. A third interview for feedback was scheduled. If the participant's scores indicated severe IBS as well as moderate to severe depression and anxiety scores, she was invited to be part of the group psychotherapy programme.

Twenty four participants were chosen, 12 for the intervention or experimental group (Group 1), which, for group therapy purposes, was subdivided into two groups of six, and 12 for the control group, (Group 2), who 
received no intervention. Each session lasted one and a half to two hours.

One month after the intervention had been completed, all 24 participants were asked to complete the measuring instruments again in order to ascertain the treatment effect as indicated by the difference in the pre-test versus post-test scores.

The post-tests included:

a) the FBDSI in order to ascertain the severity of the symptoms after the interventions;

b) the depression scale of the PAl to ascertain the depression score post intervention; and

c) the anxiety scale of the PAl to ascertain the anxiety score post intervention.

Furthermore, the 12 participants who were in the control group were offered six sessions of the individualised holistic psychotherapy after the post-tests were completed. Thus the ethical principle of equal treatment was met.

\section{Statistical Analysis}

The statistical analysis of data was done by utilising the t-test for the equality of means for between group variance (for both pre- and post-test scores) and the paired samples t-test was utilised to determine the within group variance (for both Groups 1 and 2).

\section{A SHORT-TERM HOLISTIC GROUP INTERVENTION}

IBS, like most chronic illnesses, tends to instil, support and possibly maintain a self absorbed life style which is deficient in the sense of belonging experienced through close relationships (Lammert \& Ratner, 1986:73). Using a group format is an effective way of re-establishing those links - both interpersonally where issues of individualisation, intimacy (Lammert \& Ratner, 1986:74) and illness arise, as well as dealing with intrapersonal issues of an existential meaninglessness, responsibility, choice and conflict avoidance.

The high prevalence of female participants with IBS, depression and anxiety combined with the severe dysfunction, which these participants experience also points to the need for effective group psychotherapy (Drossman \& Thompson, 1992:1009). Group therapy may be a more cost-effective form of therapy, as a group constitutes between six and eight participants with one or two therapists co-ordinating it. Lastly, very little holistic intervention has been conducted with a dearth of research occurring in South Africa. It is with this understanding that this study was undertaken.

Prior to the group intervention commencing each participant had to complete a battery of psychometric tests and had to have an initial personal interview. The interview served to identify the specific participant's needs, themes and goals for therapy, which would then be personally re-evaluated post therapy. The participants were then allotted to the appropriate group based on their personality style. The group intervention process consisted of six weekly sessions of one and a half to two hours each. An overview of the group process and holistic programme follows:

\section{Week 1}

Therapy commenced with 'setting the scene' in a general introduction where rules of the group were established. These included ethical principles of confidentiality setting, maintaining respect, inviting disclosure, questions and constructive criticism and where goals for therapy were negotiated and established (group process and cognitive projection). A Gestalt Self-Awareness exercise was conducted where members depicted a) how they perceived themselves and b) how they believed others perceived them in terms of a t-shirt design (emotional projection). This introspection was aimed at generating cohesion and making use of humour (Yalom, 1970:31). It also encouraged direct contact and expression of feelings and limited intellectualisation of the problem (Corey, 1996) (group process).

\section{Week 2}

The anatomy, physiology and treatment of IBS, depression and anxiety were discussed (somatic projection). This was followed by intense discussions of the participants' personal signs and symptoms of the disorders (Lammert \& Ratner, 1986:81) (somatic, cognitive and emotional projections). The session ended with a relaxation and ego strengthening exercise 
(behavioural and ego state projections).

\section{Week 3}

Self Awareness with issues of life-script and ego states were discussed in the group as a whole and then the group broke up into pairs to thrash out their personal needs, issues or goals for therapy (this tapped into the group process, the emotional and ego state projections and the participants' meaning axis).

\section{Week 4}

This included the dietician's lecture as well as feedback, recommendations and dietary modifications (Drossman, et al. 1992:1013) (this addressed the behavioural and cognitive projections). This generated much group discussion and further facilitated the group process.

\section{Week 5}

The following session was spent looking at the emotions which related to IBS (Lammert \& Ratner, 1986:83). This was a cathartic session where there was much support and understanding as well as learning of new coping skills. An exercise prescription for IBS, depression and anxiety was shared. This accessed the somatic, emotional, cognitive and behavioural projections and meaning axis.

\section{Week 6}

Principles of conflict handing skills and assertiveness training were discussed. Assertiveness and anxiety are largely incompatible and by having learned to assert oneself in stimulus situations that previously evoked anxiety, members deconditioned the anxiety response (Wolpe in Prochaska \& Norcross, 1994:94). Group discussion revolved around difficulties in setting boundaries and asserting one's needs. Time in the session was allocated for queries, questions and sharing areas of growth or goal formulation. This accessed the group process as well as the behavioural and cognitive projections. The group therapy programme terminated with a commitment for a post-test meeting and interview four weeks later.

Various therapeutic techniques were utilised (as highlighted above) such as cognitive therapy, gestalt psychotherapy, self-awareness, behavioural therapy, some limited solution focused therapy and logo therapy. An individual post interview and feedback session was held with each participant four weeks later where their personal themes were re-examined (from their own perspective) to subjectively measure their change and growth.

Furthermore, the post-test IBS severity score, depression scale and anxiety scale were completed and recorded. The subjects had also been asked to keep weekly variations in the qualitative rating of their IBS symptoms during therapy, which was studied for their own personal use.

Besides the group content, the process of group therapy facilitated the co-construction of meanings between all members (Boscolo, 1987) and opened up new ways of "seeing and doing". It was learnt that it was acceptable to experience and discuss their symptoms and emotions. Consequently, in their discussions they began embracing splintered aspects of their mind, body and soul.

\section{RESULTS}

There were no statistically significant differences between Group 1 (experimental group) and Group 2 (control group) regarding the various pre-intervention test scores. This result refers to the fact that the two groups can be regarded as not significantly different before treatment commenced.

A significant difference in the post-test anxiety score ( $p$ $=0.037$ ) at the $5 \%$ level of significance between Group 1 and Group 2 was found. The mean of the post-test anxiety score for Group 1 was $0=56.4167$ versus Group 2 was $0=66.9167$. No statistically significant differences between Group 1 and 2 in terms of post-test scores were found for their IBS severity score or their depression score.

In Group 1, statistically significant differences between the pre- and post-intervention scores were reported in terms of anxiety $(p=0.014$; significant at $5 \%$ level; $0=$ 69.9091 versus $0=57.0909)$ and depression $(p=0.002$; significant at the $1 \%$ level; $0=69.6667$ versus $0=$ 55.9167). No such difference was found in terms of IBS 
severity scores. No significant differences were found in the pre- versus post-intervention scores of Group 2 (control group).

\section{DISCUSSION}

To summarise the findings, the holistic short-term group psychotherapy for participants with severe IBS and moderate to severe depression and anxiety was effective in reducing anxiety statistically significantly. Depression scores were also significantly reduced for the participants within the experimental group, while severe IBS symptoms remained unchanged.

The literature verifies the IBS severity scores remaining unchanged after intervention. Drossman and Thompson (1992:1015) state that individuals with intractable or severe IBS symptoms together with a comorbid depression and anxiety may frequently be unresponsive to traditional psychotherapy. The percentage of IBS individuals who fall into this category is approximately 5\% (Drossman \& Thompson, 1992:1014). Given that both Group 1 and Group 2 had participants with severe IBS and moderate to severe depression and anxiety, it is not surprising that these IBS symptoms did not improve over a six-week period. Research has shown that these individuals often present with abnormal illness behaviours and neurotic traits (Stuart, Pretorius, et al. 1999:29). This means that they will generally have symptom constancy, severe concomitant psychiatric disorders and their activity and daily functioning will be severely disrupted. They may also be unresponsive to gut-directed pharmacotherapy (Drossman \& Thompson, 1992:1015). In a similar vein, Lammert and Ratner (1986:87) found that in their study of a self-selected group of IBS participants, $33 \%$ of the participants experienced an increase in IBS symptom severity post intervention.

Further speculation about the lack of IBS symptom severity change with intervention could relate to the type of intervention being implemented. In this research study, much of the psychoeducation was aimed at helping the participants gain an understanding of the anatomical and physiological underpinnings of IBS. With this education, it is possible that a greater understanding of the syndrome led to a heightened awareness and therefore a closer monitoring of the symptoms. Research conducted by Creed and Guthrie (1989:1603) with constipated IBS individuals has shown that psychotherapy with this particular group of individuals needs to be continued for a longer duration. A large proportion of the present experimental group also reported constipated patterns. Therefore a research intervention of a longer duration may be required in order to alter severe IBS symptomatology. Furthermore, resistant cases were selected for this sample as previous research offered little positive outcomes for these individuals. Therefore, if a positive result could be obtained from this resistant group, it is suggested that less resistant IBS individuals with a comorbid depression and anxiety could possibly benefit far more from similar intervention programmes.

Due to the severe nature of IBS and depression in this sample, a longer duration of psychotherapy with possible referral for psychopharmacotherapy as an adjunct, would have been advisable. However, the intervention was successful in significantly reducing the depression scores of the experimental subjects. This contradicts Drossman and Thompson's' (1992:1016) findings that subjects with intractable IBS symptoms with a comorbid depression do not usually respond to psychotherapy. This has important implications for future IBS interventions. Similarly, anxiety was also improved after the intervention for Group 1 (the experimental group). This also contradicts Drossman and Thompson's' (1992:1016) findings that subjects with intractable IBS and anxiety do not usually respond to psychotherapy.

The post-test scores for Group 2 (the control group who received no intervention) showed that there was no significant change in any of the symptoms under investigation after six weeks of no intervention. There were no spontaneous recoveries and it is feasible that non-specific factors such as expectancy, anticipation and increased negative perceptions may have exacerbated negative outcomes.

The study was limited by various factors, some of which are highlighted here. Firstly, limited generalisability needs to be considered because of the relative homogeneous sample. Future research should include, for example, black participants. Although groups were matched in terms of gender, age, IBS severity, depression and anxiety, randomisation was impossible, which limits generalisability. 
History and maturation variables may have distorted the post-test results of the experimental group as the recruitment for this group took approximately eight months. Much less time was needed to recruit the control group because these participants did not need to be matched.

Lastly, the PAI has not been standardised for use in South Africa. The test was selected due to its applicability within a western society population. Further research however needs to be conducted with respect to the South African population.

\section{CONCLUSION}

This article presented a discussion of the results of a short-term holistic group intervention for the treatment of severe IBS with its comorbid depression and anxiety. The benefits of the holistic group intervention together with the limitations and strengths of the research design have been elucidated. The results have indicated that holistic short-term group intervention is successful in significantly decreasing the depression and anxiety scores, but not the IBS severity scores. It is recommended that for refractory cases, the holistic group intervention programme be extended to eight to ten weeks (with a duration of one and a half to two hour sessions) as this could possibly reduce IBS symptom severity.

In addition, when the participants within the group can feel safe to begin embracing the "split-off" or shadow parts of themselves and tolerate what has to be faced, together with the range of feelings which erupt around that (Dowrick, 1997:6), they can begin "tapping" into their own inner strength. It is then that language, feelings and the awareness can begin to unmask the somatic symptoms that have their roots in unspeakable dilemmas.

A classic psychosomatic disorder such as IBS essentially requires an interdisciplinary team approach so that the multiple dimensions of the illness can be holistically addressed. Not only are psychologists increasingly being consulted regarding the psychosomatic disorders, but there is a growing consensus among the multidisciplinary health-care team, that the psychologist is most appropriately placed at the fulcrum of the client's mind, body, soul axis (Stuart, Pretorius, et al. 1999:35).

\section{RECOMMENDATIONS}

- Unfortunately the sample that was selected was not representative of the multi cultures in South Africa. Therefore it is recommended that further group research be conducted within South Africa across multicultural boundaries in order to be able to generalise the results to the wider community.

- $\quad$ The benefits which a cohesed IBS group offers each other have been briefly described above. There is much place for more contact groups of this nature where mutual understanding, bonding, caring, learning of skills and making new choices can occur. This needs to be developed despite the difficulty in recruiting homogeneous groups for short to medium term group psychotherapy.

- $\quad$ In the control group, three out of twelve participants (or 25\%) had learning disorders. The only known study that broached part of this was Wender and Kalm (1983) (in Wilson, 1997:36) who studied Attention Deficit Disorder (ADD) in IBS individuals. Out of their IBS sample, 27\% had ADD. It would be interesting to research this variable in more detail.

- Having been in contact with members of Group 1 (the experimental group - who received intervention) three years later, there seems to be a tendency, amongst more than half of them, of less severe and more manageable IBS symptoms. These perceptions would require further research.

- There is a strong belief system in both the experimental and control groups. It would be interesting to explore the role of religion in IBS.

\section{ETHICAL MEASURES}

The ethical code of professional conduct, put forward by the Professional Board for Psychology Health Professions Council of South Africa, was adhered to for this study. Specifically, the participants gave informed consent pertaining to the present study, they were informed about the aims of the study and the outcomes of the study were communicated to participants. The 
results were disseminated at international and national congresses.

\section{REFERENCES}

Alwood, CW \& Gagiano, CA eds. 1997: Handbook of psychiatry for primary care. Cape Town: Oxford University Press.

Boscolo, L 1987: Milan systemic Family Therapy: Conversations in theory and practice. New York: Basic Books.

Corey, E 1996: Theory and practice of counselling and psychotherapy; fifth edition. California: Brooks/Cole.

Creed, F \& Guthrie, E 1989: Psychological treatment of the irritable bowel syndrome: A review. Gut, 30, 1989:1601-1609.

Dolan, L 2000: The treatment of irritable bowel syndrome: A holistic approach. Johannesburg: Rand Afrikaans University. (MA Dissertation.)

Dowrick, S 1997: Forgiveness and other acts of love. Australia: Penguin Books.

Drossman, DA 1989: Irritable bowel Syndrome. American Family Physician, 39, 1989:159-164.

Drossman, DA ed. 1994: The functional gastrointestinal disorders. Diagnosis, pathophysiology and treatment: A multinational consensus. USA: Little, Brown and Co.

Drossman, DA \& Thompson, WG 1992: The irritable bowel syndrome: Review and a graduated multicomponent treatment approach. Annals of Internal Medicine, 116(12), 1992:1009-1016.

Drossman, DA; Thompson, WG \& Whitehead, WE 1992: Approaching IBS with confidence. Patient Care, 26(13), 1992:175-210.

Drossman, DA; Zhiming, LI; Toner, BB; Diamant, NE; Creed, FH; Thompson, D; Read, N; Babbs, C; Barreiro, M; Bank, L; Whitehead, WE; Schuster, MM \& Guthrie, EA, 1995: Functional bowel disorders: A multicenter comparison of health status and development of illness severity index. Digestive Diseases and Sciences, 40(5), 1995:986995.

Duncan, GH; Bushnell, MC \& Lavigne, GJ 1989: Comparison of verbal and visual analog scales for measuring the intensity and unpleasantness of experimental pain. Pain, 37, 1989:295-303.

Els, C; Gagiano, CA; Grundling, H de K; van Zyl, J \& Joubert, G 1995: A study of psychiatric illness in patients with irritable bowel syndrome. South African Medical Journal, 85(12), 1995:1368-1372. Esler, MD \& Goulston, KJ 1973. Levels of anxiety in colonic disorders. New England Journal of Medicine, 288, 1973:16-20.

Guthrie, E; Creed, F; Dawson, D \& Tomenson, B 1991: A controlled trial of psychological treatment for the irritable bowel syndrome.

Gastroenterology, 100, 1991:450-457.

Kaplan, HI; Sadock, BJ \& Grebb, JA 1994: Synopsis of psychiatry; seventh edition. Baltimore: Williams \& Wilkins.

Keller, M 1996: The treatment of recurrent and chronic depression.
South African Medical Journal, November 1996:10-16.

Kellow, JE; Langeluddecke, PM; Eckersley, GM; Jones, MP \& Tennant, CC 1992: Effects of acute psychological stress on small-intestinal motility in health and the irritable bowel syndrome. Scandinavian Journal of Gastroenterology, 27, 1992:53-58.

Lammert, M \& Ratner, M 1986: Group treatment of patients with irritable bowel syndrome. Social Work in Health Care, 12(1), 1986:6788.

Langeluddecke, PM 1985: Review: Psychological aspects of irritable bowel syndrome. Australian and New Zealand Journal of Psychiatry, 19, 1985:218-226.

Lydiard, RB; Laraia, MT; Howell, EF \& Ballenger, JC 1986: Can panic disorder present as irritable bowel syndrome? Journal of Clinical Psychiatry, 47(9), 1986:470-473.

Morey, LC 1991: Personality Assessment Inventory: Professional manual. Florida: Psychological Assessment Resources.

Prochaska, JD \& Norcross, JC 1994: Systems of psychotherapy: A transtheoretical analysis; third edition. California: Brooks/Cole.

Segal, I \& Waker, ARP 1984: The irritable bowel syndrome in the black community. South African Medical Journal, 65, 1984:73-74. Spielberger, CD 1966: Anxiety and behaviour. New York: Academic. Stuart, AD; Pretorius, G; Stanley, J; Rossouw, E; Nel, P; Dolan, L \& Bush, C 1999: A paradigmatic shift in the conceptualization and treatment of irritable bowel syndrome. European Congress of Psychology. Symposium (6th : 1999: Rome).

Svedlund, J; Sjodin, I; Dotevall, G \& Gillberg, R 1984: Upper gastrointestinal and mental symptoms in the irritable bowel syndrome. Scandinavian Journal of Gastroenterology, 20(3), 1984:199-202. Thompson, WG 1984: The irritable bowel: Progress report. Gut, 25, 1984:305-320.

Walker, EA; Roy-Byme PP; Katon WJ; Li, L; Amos, D \& Jiranek, G 1990: Psychiatric iliness and irritable bowel syndrome: A comparison with inflammatory bowel disease. American Journal of Psychiatry, 147(12), 1990:1656-1661.

Wilson, MH 1997: The incidence of concurrent psychopathology in patients suffering from irritable bowel syndrome. Johannesburg: Rand Afrikaans University. (MA Dissertation.)

Yalom, ID 1970: The theory and practice of group psychotherapy; third edition. USA: Harper Collins. 